\title{
Concerted Action of CB1 Cannabinoid Receptor and Deleted in Colorectal Cancer in Axon Guidance
}

\author{
Anteneh Argaw, ${ }^{1,2}$ Gabriel Duff, ${ }^{2,3}$ Nawal Zabouri, ${ }^{2}$ Bruno Cécyre, ${ }^{2}$ Natacha Chainé, ${ }^{2}$ Hosni Cherif, ${ }^{2}$ Nicolas Tea, ${ }^{2}$ \\ Beat Lutz, ${ }^{4}$ Maurice Ptito, ${ }^{2}$ and Jean-François Bouchard ${ }^{2,3}$ \\ ${ }^{1}$ Biomedical Sciences, Faculty of Medicine, University of Montreal, Montreal, Quebec H3T 1J4, Canada, ${ }^{2}$ School of Optometry, University of Montreal, \\ Montreal, Quebec H3T 1P1, Canada, ${ }^{3}$ Faculty of Pharmacy, University of Montreal, Montreal, Quebec H3C 3J7, Canada, and ${ }^{4}$ Institute of Physiological \\ Chemistry, University Medical Center Mainz, 55128 Mainz, Germany
}

Endocannabinoids (eCBs) are retrograde neurotransmitters that modulate the function of many types of synapses. The presence of eCBs, their $\mathrm{CB} 1$ receptor $(\mathrm{CB} 1 \mathrm{R})$, and metabolizing enzymes at embryonic and early postnatal periods have been linked to developmental processes such as neuronal proliferation, differentiation, and migration, axon guidance, and synaptogenesis. Here, we demonstrate the presence of a functional eCB system in the developing visual system and the role of CB1R during axon growth and retinothalamic development. Pharmacological treatment of retinal explants and primary cortical neuron cultures with ACEA, a selective CB1R agonist, induced a collapse of the growth cone (GC). Furthermore the application of AM251, a CB1R inverse agonist, to the neuronal cultures increased the surface area of GC. In vivo, intraocular injection of ACEA diminished retinal projection growth, while AM251 promoted growth and caused aberrant projections. In addition, compared with their wild-type littermates, CB1R-deficient adult mice revealed a lower level of eye-specific segregation of retinal projections in the dorsal lateral geniculate nucleus. Finally, we found that pharmacological modulation of CB1R affected the trafficking of Deleted in colorectal cancer (DCC) receptor to the plasma membrane in a PKAdependent manner. Moreover, pharmacological inhibition or genetic inactivation of DCC abolished the CB1R-induced reorganization of the GC. Overall, these findings establish a mechanism by which the CB1R influences GC behavior and nervous system development in concerted action with DCC.

\section{Introduction}

Marijuana is one of the most commonly abused drugs by women of reproductive age (Ebrahim and Gfroerer, 2003; Substance Abuse and Mental Health Services Administration, Office of Applied Studies, 2008; Hanus, 2009). This is important to consider, as there is mounting evidence that prenatal exposure has been associated with deleterious neurobehavioral consequences in the offspring (Jutras-Aswad et al., 2009). The underlying mecha-

Received Aug. 20, 2009; revised Aug. 30, 2010; accepted Nov. 16, 2010.

This work is supported by a grant to J.-F.B. from the Canadian Institutes of Health Research (CIHR). A.A. was supported by a doctoral research award from E.A. Baker Foundation and the Institute of Neurosciences, Mental Health and Addiction of the CIHR. G.D. was supported by a studentship from the Fonds de la recherche en santé du Québec (FRSQ). M.P. holds the Harland Sanders Chair for Visual Science. J.-F.B. holds a Chercheur Junior 2 Award from the FRSQ. We thank Robert Weinberg for the dec transgenic mice. We thank Matthieu Vanni for the image analysis script programmed with MatLab software and Florence Dotigny, Marc Dufresne, Sophie Charron, and Denis Latendresse for their excellent technical assistance. A.A. designed the project, performed the retinal explants, primary neuron cultures, growth cone turning assay, intraocular injections, immunohistochemistry and immunocytochemistry experiments, and statistical analysis, analyzed imaging data, and prepared the manuscript. G.D. performed the retinal explants, primary neuron cultures, growth cone turning assay, and immunohistochemistry and immunocytochemistry experiments, and analyzed imaging data. N.Z. and B.C. executed the immunohistochemical experiments. H.C. and N.C. performed and analyzed additional immunocytochemistry experiments. N.T. performed the Western blot analysis. B.L. kindly provided the CB1R transgenic mouse developed by his research team and contributed to the preparation of the manuscript. M.P. and J.-F.B. designed and supervised the project, performed the biotinylation experiments, and contributed to the preparation of this manuscript.

Correspondence should be addressed to Jean-François Bouchard, School of Optometry, University of Montreal, 3744 rue Jean-Brillant, Office 260-7, Montreal, Quebec H3T 1P1, Canada. E-mail: Jean-Francois. Bouchard@umontreal.ca.

D0I:10.1523/JNEUROSCI.4134-09.2011

Copyright $\odot 2011$ the authors $\quad 0270-6474 / 11 / 311489-11 \$ 15.00 / 0$ nisms of the detrimental effects of cannabis on the developing nervous system have not been well understood to date, but the recent insights into the constituents and the functioning of the endocannabinoid (eCB) system have promoted possible mechanisms of action. Anandamide and 2-arachidonoylglycerol are the main eCBs, modulating synaptic transmission in many brain regions (Kano et al., 2009). eCB actions are primarily mediated by the $\mathrm{CB} 1$ and $\mathrm{CB} 2$ receptors $(\mathrm{CB} 1 \mathrm{R}, \mathrm{CB} 2 \mathrm{R})$, but other receptor systems have also been implicated in eCB signaling (Ryberg et al., 2007; Mackie, 2008). Recent studies implicate the eCB system in a wide variety of developmental events, such as cell proliferation and migration, and axon guidance during CNS development (Berghuis et al., 2005, 2007; Harkany et al., 2008; Mulder et al., 2008; Watson et al., 2008; Keimpema et al., 2010; Wu et al., 2010). In particular, the $\mathrm{CB} 1 \mathrm{R}$ has been reported to regulate pyramidal cell specification, GABAergic interneuron development, and cortical neuron growth (Berghuis et al., 2007; Mulder et al., 2008; Vitalis et al., 2008; Keimpema et al., 2010; Wu et al., 2010). Berghuis et al. (2007) reported that CB1R induces GC collapse by activating RhoA, an intracellular protein regulating cytoskeletal rearrangements. Recent investigations also allocated important functions to the eCB synthesis and degradation machinery in the control of axon growth and guidance (Keimpema et al., 2010). Nonetheless, the mechanisms by which eCBs influence GC reorganization during axon guidance have remained to be elucidated.

Here, the involvement of the eCB system in the development of the visual system was investigated. During embryogenesis, ret- 
inal ganglion cell (RGC) axons navigate through distinct anatomical structures before reaching their targets. Axons enter the optic disc, penetrate the optic nerve head, cross the optic chiasm, and finally connect with their thalamic [dorsal lateral geniculate nucleus (dLGN) and lateral posterior] and midbrain [superior colliculus (SC)] targets in the appropriate hemisphere (Isenmann et al., 2003). Growth of RGC axons is largely directed by guidance cues present in their environment, including netrin-1, slits, and ephrins (Inatani, 2005). Their respective receptors (DCC, Robo, and Eph) located at the growth cone (GC) transduce guidance signals to a cytoplasmic gradient of molecules, resulting in the formation of functional retinofugal connections (Sanford et al., 2008).

We used the rodent neurovisual system and primary cortical neuron cultures (for biochemical assays requiring a large amount of neurons) to demonstrate a mechanism by which eCBs influence axon guidance. We found that the developing visual system expresses the $\mathrm{CB} 1 \mathrm{R}$ and the eCB-synthesizing and -degrading enzymes. Furthermore, pharmacological manipulation of the CB1R affects RGC growth and retinothalamic development. Importantly, we observed that the DCC receptor is necessary for CB1R-induced reorganization of the GC.

\section{Materials and Methods}

All animal experiments were approved by the Comité de déontologie de l'expérimentation sur les animaux from the University of Montreal and were handled in accordance with the recommendations provided by the Canadian Council on Animal Care. CB1R knock-out mice were generated and genotyped as previously described (Marsicano et al., 2002). dcc transgenic mice were obtained from Robert Weinberg (Whitehead Institute for Biomedical Research, Cambridge, MA) and were genotyped as described previously (Fazeli et al., 1997). All surgical procedures were performed under deep general anesthesia using either hypothermia [pups $<$ postnatal day 4 (P4)] or isoflurane.

Reagents. Bovine serum albumin (BSA), brain-derived neurotrophic factor (BDNF), ciliary neurotrophic factor (CNTF), dibutyryl cAMP (db-cAMP), DNase, forskolin (FSK), Hoechst 33258, insulin, KT5720, laminin, monoclonal anti- $\beta$-actin, monoclonal anti-MAP kinase (diphosphorylated Erk-1\&2), poly-D-lysine, progesterone, putrescine, pyruvate, selenium, apo-transferrin, triiodo-thyronine, trypsin, anti-syntaxin, and anti-CB1R were purchased from Sigma. ACEA, AM251, and O2050 were purchased from Tocris Bioscience. B27, N2, Dulbecco's PBS (DPBS), fetal bovine serum (FBS), glutamine, Neurobasal media, penicillin-streptomycin, S-MEM, and sodium pyruvate were purchased from Invitrogen. Papain solution was from Worthington Biochemical, normal donkey serum (NDS) from Jackson ImmunoResearch Laboratories, and ovomucoid from Roche Diagnostics. Rabbit anti-mouse macrophage and mouse anti-Thy-1.2 monoclonal IgM $(\mu$ chain specific) were obtained from Accurate Chemical. Anti-cAMP, antiERK, and anti-GAP-43 were from Millipore Bioscience Research Reagents. Antibodies directed against CB1R, MGL, and FAAH were purchased from Cayman. Anti-NAPE-PLD and DAGL $\alpha$ were kind gifts from Ken Mackie (Department of Psychological and Brain Sciences, Indiana University, Bloomington, IN). Monoclonal DCC antibodies against extracellular $\left(\mathrm{DCC}_{\mathrm{EX}}, \mathrm{G} 92-13\right)$ or intracellular $\left(\mathrm{DCC}_{\mathrm{IN}}, \mathrm{G} 97-\right.$ 449) epitopes of DCC were obtained from PharMingen. $\alpha$ DCCfb AF5, H89, and LNAC were purchased from EMD. Goat and HRP-coupled secondary antibodies raised against rabbit IgG $(\mathrm{H}+\mathrm{L})$ or mouse $\operatorname{IgM}(\mu$ chain specific) were from Jackson ImmunoResearch Laboratories, and L1 and Alexa Fluor-conjugated secondary antibodies (Alexa 488 and Alexa 546) were from Invitrogen. Avidin-biotin-peroxidase complex $\mathrm{ABC}$ Kit and donkey anti-goat biotinylated secondary antibody were from Vector Labs. The B fragment of the cholera toxin $(\mathrm{CTb})$ and goat anti-CTb antibody were from List Biological Laboratories.

Retinal explant culture. Mouse embryonic day 14 (E14)-E15 embryo retinas were isolated and dissected in small segments in DPBS and plated on $12 \mathrm{~mm}$ glass coverslips previously coated with poly-D-lysine $(20 \mu \mathrm{g} /$ $\mathrm{ml})$ and laminin $(5 \mu \mathrm{g} / \mathrm{ml})$ in 24-well plates. Explants were cultured in
Neurobasal supplemented with $100 \mathrm{U} / \mathrm{ml}$ penicillin, $100 \mu \mathrm{g} / \mathrm{ml}$ streptomycin, $5 \mu \mathrm{g} / \mathrm{ml}$ LNAC, $1 \%$ B27, $40 \mathrm{ng} / \mathrm{ml}$ selenium, $16 \mu \mathrm{g} / \mathrm{ml}$ putrescine, $0.04 \mathrm{ng} / \mathrm{ml}$ triiodo-thyronine, $100 \mu \mathrm{g} / \mathrm{ml}$ transferrin, $60 \mathrm{ng} / \mathrm{ml}$ progesterone, $100 \mu \mathrm{g} / \mathrm{ml} \mathrm{BSA}$, sodium pyruvate $(1 \mathrm{~mm})$, glutamine $(2 \mathrm{~mm})$, CNTF $(10 \mathrm{ng} / \mathrm{ml})$, insulin $(5 \mu \mathrm{g} / \mathrm{ml})$, and FSK $(10 \mu \mathrm{M})$ at $37^{\circ} \mathrm{C}$ and $5 \%$ $\mathrm{CO}_{2}$. Explants were treated for $15 \mathrm{~h}$ at day in vitro 0 (DIV0) for projections analysis or $1 \mathrm{~h}$ at DIV1 for growth cone analysis. Photomicrographs were taken using an Olympus BX51WI microscope (Olympus Canada) and analyzed with Image Pro Plus 5.1 software (Media Cybernetics). The total length of axon bundles was quantified and expressed as mean \pm SEM. Statistical significance of differences between means was evaluated by ANOVA with Bonferroni's post hoc test (Systat).

Purified retinal ganglion cell culture. RGCs from P7-P8 mice (Charles River) were purified and cultured according to a protocol previously described by Barres et al. (1988). In brief, following enucleation, retinas were dissected and enzymatically dissociated, at $37^{\circ} \mathrm{C}$ for $30 \mathrm{~min}$, in a papain solution (15 U/ml in DPBS) containing $1 \mathrm{~mm} 1$-cysteine. The retinas were then triturated sequentially, with a $1 \mathrm{ml}$ pipette, in a solution containing ovomucoid $(1.5 \mathrm{mg} / \mathrm{ml})$, DNase $(0.004 \%)$, BSA $(1.5 \mathrm{mg} / \mathrm{ml})$, and rabbit antibodies directed against mouse macrophages (1:75) to yield a suspension of single cells. The suspension was centrifuged and washed in a high concentration ovomucoid-BSA solution $(10 \mathrm{mg} / \mathrm{ml}$ for each in DPBS). The dissociated cells were resuspended in DPBS containing BSA $(0.2 \mathrm{mg} / \mathrm{ml})$ and insulin $(5 \mu \mathrm{g} / \mathrm{ml})$.

RGCs were purified using the two-step panning procedure (Barres et al., 1988; Meyer-Franke et al., 1995). Briefly, to remove macrophages, the retinal suspension was incubated at room temperature in Petri dishes coated with affinity-purified goat anti-rabbit $\operatorname{IgG}(\mathrm{H}+\mathrm{L})$. The nonadherent cells were then transferred to a Petri dish that had been coated with affinity-purified goat anti-mouse IgM ( $\mu$ chain specific) followed by anti-Thy-1.2 monoclonal IgM. The adherent RGCs were first released enzymatically by incubating them in a $0.125 \%$ trypsin solution at $37^{\circ} \mathrm{C}$ and $5 \% \mathrm{CO}_{2}$ followed by manually pipetting an enzyme inhibitor solution (30\% FBS in Neurobasal) along the surface of the dish.

Purified RGCs were plated on poly-D-lysine- $(10 \mu \mathrm{g} / \mathrm{ml})$ and laminin$(5 \mu \mathrm{g} / \mathrm{ml}$ ) coated glass coverslips (number 0 Deckgläser; Carolina Biological) in 24-well plates. RGCs were cultured in $600 \mu$ l of serum-free medium modified from Bottenstein and Sato (1979). Neurobasal media was supplemented with B27, selenium, putrescine, triiodo-thyronine, transferrin, progesterone, pyruvate (1 mM), glutamine ( $2 \mathrm{~mm}), \mathrm{CNTF}$ (10 $\mathrm{ng} / \mathrm{ml}), \operatorname{BDNF}(50 \mathrm{ng} / \mathrm{ml})$, insulin $(5 \mu \mathrm{g} / \mathrm{ml})$, and FSK $(10 \mu \mathrm{M})$. RGCs were cultured at $37^{\circ} \mathrm{C}$ and $5 \% \mathrm{CO}_{2}$. All experiments on purified RGCs were performed $36-40 \mathrm{~h}$ following plating.

Primary neuron culture. Primary cortical neurons are used in the present study because of the large amount of cells that can easily be cultured and harvested for biochemical assays, as opposed to RGC cultures. Staged pregnant CD1 mice were obtained from Charles River. E14-E15 embryo brains were dissected and the superior layer of each cortex was isolated and transferred in $2 \mathrm{ml}$ of S-MEM at $37^{\circ} \mathrm{C}$ with $2.5 \%$ trypsin and $2 \mathrm{mg} / \mathrm{ml}$ DNase for $15 \mathrm{~min}$. Pellet was transferred into $10 \mathrm{ml}$ of S-MEM with $10 \%$ FBS and stored at $4^{\circ} \mathrm{C}$. Following centrifugation, pellet was again transferred in $2 \mathrm{ml}$ of S-MEM with $10 \%$ FBS and triturated three to four times. Supernatant was transferred in $10 \mathrm{ml}$ of Neurobasal medium. Dissociated cells were counted and plated at 50,000 cells per well on $12 \mathrm{~mm}$ glass coverslips previously coated with poly-D-lysine $(20 \mu \mathrm{g} / \mathrm{ml})$. Cells were cultured for $2 \mathrm{~d}$ in Neurobasal medium containing $1 \% \mathrm{~B}-27,100 \mathrm{U} / \mathrm{ml}$ penicillin, $100 \mu \mathrm{g} / \mathrm{ml}$ streptomycin, $0.25 \% \mathrm{~N} 2$, and $0.5 \mathrm{~mm}$ glutamine. Wells were treated with either a CB1R agonist (50 nM ACEA) or a CB1R inverse agonist (300 nм AM251) combined with adenylate cyclase activator $(10 \mu \mathrm{M}$ FSK) or PKA inhibitors $(200 \mathrm{~nm}$ KT5720 and $2 \mu \mathrm{M} \mathrm{H} 89$ ), respectively, for $60 \mathrm{~min}$ for GC morphology or 15 min for cAMP and PKA immunoreactivities. In another set of experiments, neurons were treated for 15 min with DCC function-blocking antibody ( $\alpha \mathrm{DCCfb} ; 3.5 \mu \mathrm{g} / \mathrm{ml}$ ), followed by $1 \mathrm{~h}$ stimulation with AM251, O2050, or FSK.

Growth cone turning assay. Embryonic retinal explants were cultured on a coverglass in a borosilicate chamber (Lab-Tek) for 2 DIV and placed in an incubator mounted on an inverted microscope (Olympus IX71). They were kept at $37^{\circ} \mathrm{C}$ and $5 \% \mathrm{CO}_{2}$ with a Live Cell chamber (Neve 
Bioscience) throughout the whole experiment. A gradient was created using a micro-injector (Picoplus, Harvard Apparatus). The diameters of the tips of the glass microelectrodes used to eject the pharmacological agents were $<3 \mu \mathrm{m}$ and the tip was positioned at $\sim 45^{\circ}$ and $\sim 100 \mu \mathrm{m}$ away from the GC of interest.

Immunocytochemistry. Following treatments, retinal explants, RGCs, and primary cortical neuron cultures were washed with PBS, $\mathrm{pH} 7.4$, fixed in 4\% paraformaldehyde, $\mathrm{pH} 7.4$, and blocked with $2 \%$ normal goat serum (NGS) and 2\% BSA in PBS containing 0.1\% Tween 20, pH 7.4, for $30 \mathrm{~min}$ at room temperature. Neurons were then incubated overnight at $4^{\circ} \mathrm{C}$ in blocking solution containing anti-GAP-43 (1:1000) for GC morphology analysis, anti-cAMP (1:1000), anti-CB1R (1:1000), anti-NAPEPLD (1:200), anti-DAGL $\alpha$ (1:200), anti-FAAH (1:100), anti-MGL (1:

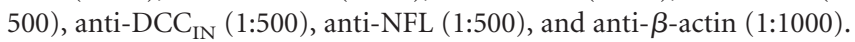
The following day, cells were washed and labeled with Alexa secondary antibodies (488 and 546) and Hoechst 33258, and the coverslips were mounted with Immu-Mount (Thermo Scientific).

Surface biotinylation. Cortical neurons from E14-E15 embryo cortices were dissociated, plated, and cultured for 2 DIV at a density of $\sim 2,000,000$ cells per $100 \mathrm{~mm}$ PDL-coated tissue culture dish. Then, cells were treated with $300 \mathrm{~nm}$ AM251, $300 \mathrm{~nm} \mathrm{O} 2050,10 \mu \mathrm{M}$ FSK, $200 \mathrm{~nm}$ KT5720 + AM251, $2 \mu \mathrm{M}$ H89 + AM251, KT5720 + FSK, or H89 + FSK for $1 \mathrm{~h}$. Neurons were then washed with ice-cold PBS containing $0.1 \mathrm{~mm}$ calcium chloride and $1 \mathrm{~mm}$ magnesium chloride, $\mathrm{pH} 7.4$, to halt protein trafficking. Surface biotinylation was performed by adding EZ-Link Sulfo-NHS-LC-biotin (Thermo Scientific), $5 \mathrm{ml}$ per plate at $0.5 \mathrm{mg} / \mathrm{ml}$ in $\mathrm{PBS}$ at $4^{\circ} \mathrm{C}$ for $30 \mathrm{~min}$ (Bouchard et al., 2004); this was then removed, and the reaction was quenched by the addition of $5 \mathrm{ml}$ of $10 \mathrm{~mm}$ ice-cold glycine in $\mathrm{PBS}$ at $4^{\circ} \mathrm{C}$ for two periods of $10 \mathrm{~min}$. Subsequently, cell cultures were washed twice with $5 \mathrm{ml}$ of ice-cold PBS and lysed with RIPA buffer. Biotinylated proteins were precipitated with streptavidin-agarose (Thermo Scientific) and analyzed by Western blot.

Western blot analysis. Dissociated primary cortical neurons were cultured for $2 \mathrm{DIV}$ at a density of $\sim 250000$ cells/dish in $35 \mathrm{~mm}$ poly-Dlysine-coated Petri dishes. After treatment, cells were washed once with pH 7.4 ice-cold PBS and then lysed with Laemmli sample buffer. Primary antibodies were used at the following concentrations: anti-CB1R (1:1000),

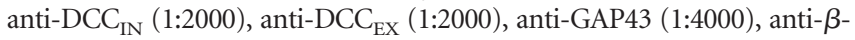
actin (1:5000), anti-AKT (1:1000), anti-p-AKT (1:1000), anti-ERK1/2 (1: 5000), anti-p-ERK1/2 (1:2000), anti-S6 (1:2000), and anti-p-S6 (1:2000). Results were visualized using chemiluminescence (PerkinElmer).

Intraocular injections. Syrian golden hamsters (Charles River) were used for studies investigating, in vivo, the implication of the CB1R during retinal ganglion cell projection growth during postnatal development. These mammals are born with a premature nervous system (Clancy et al., 2001). Twenty-four hours following birth, at P1, anesthetized hamsters received a unilateral injection of $2 \mu$ l solution of $\mathrm{CTb}$, a highly sensitive anterograde tracer, with either $0.9 \%$ saline solution, a $300 \mu \mathrm{M}$ concentration of the CB1R agonist ACEA, or $300 \mu \mathrm{M}$ AM251, a CB1R inverse agonist (supplemental Fig. $4 \mathrm{~A}$, available at www.jneurosci.org as supplemental material). Briefly, under an operating microscope, a small incision was made in the eyelids to access to the right eye. The injections were administered using a glass micropipette attached to a $10 \mu \mathrm{l}$ Hamilton syringe. The micropipette was carefully inserted into the vitreous at an angle to avoid damage to the lens. Following the injection, the eyelids were closed with surgical glue (Vetbond; $3 \mathrm{M}$ ).

Perfusion. At P5, 4 d postinjection, anesthetized hamsters were perfused transcardially with $0.1 \mathrm{M}$ PBS, $\mathrm{pH} 7.4$, followed by $4 \%$ paraformaldehyde in PBS. The brains were removed, postfixed overnight at $4^{\circ} \mathrm{C}$, and cryoprotected by infiltration of buffered sucrose. The brains were then frozen and kept at $-80^{\circ} \mathrm{C}$ until further processing.

Immunohistochemistry. The presence of the $\mathrm{eCB}$ system during early postnatal development was investigated by immunohistochemistry. The RGC fiber layer was labeled with syntaxin. Retinal sections were washed in $0.1 \mathrm{M}$ PBS, postfixed for $5 \mathrm{~min}$ in a $70 \%$ solution of ethanol, rinsed in $0.03 \%$ Triton X-100 in buffered saline, and blocked in 10\% NDS (Jackson ImmunoResearch Laboratories) and 0.5\% Triton X-100 in buffered saline for $1 \mathrm{~h}$. The sections were then coincubated overnight in rabbit anti-CB1R, rabbit anti-NAPE-PLD, goat anti-DAGL $\alpha$, rabbit anti-
FAAH, or rabbit anti-MGL solution with an antibody tagged as mouse and directed against syntaxin. After incubation with the primary antibodies, the sections were washed in buffered saline, blocked for $30 \mathrm{~min}$, and incubated for $1 \mathrm{~h}$ with secondary antibodies: Alexa donkey antirabbit 555 for CB1R, NAPE-PLD, FAAH, or MGL, Alexa donkey antigoat 555 for DAGL $\alpha$, and Alexa donkey anti-goat or mouse 488 for cell type markers (Invitrogen). After washes, the sections were mounted with a homemade Dabco-PVD mounting media (Ono et al., 2001).

The effects of intraocular injection of CB1R agonist, inverse agonist, and antagonist were visualized by immunohistochemistry according to a protocol previously described (Argaw et al., 2008). Briefly, 40- $\mu$ m-thick coronal sections of tissue were incubated in $90 \%$ methanol and $0.3 \%$

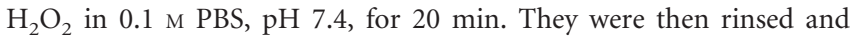
incubated in $0.1 \mathrm{M}$ glycine in PBS for $30 \mathrm{~min}$, followed by an overnight incubation $\left(4^{\circ} \mathrm{C}\right)$ in PBS containing $4 \%$ NDS, $2.5 \%$ BSA, and $1 \%$ Triton $\mathrm{X}-100$. Sections were subsequently rinsed and immersed for $48 \mathrm{~h}$ at room temperature in a solution containing goat anti-CTb diluted 1:4000 in PBS with 2\% NDS, $2.5 \%$ BSA, and 2\% Triton X-100. Afterward, sections were rinsed and incubated in 2\% NDS and 2.5\% BSA/PBS for $10 \mathrm{~min}$. This was followed by a $1 \mathrm{~h}$ incubation in donkey anti-goat biotinylated secondary antibody diluted 1:200 in PBS with 2\% NDS, 2.5\% BSA, and $1 \%$ Triton X-100. Tissue was rinsed, incubated in 2\% NDS and $2.5 \%$ BSA in PBS for $10 \mathrm{~min}$, and subsequently processed by an avidin-biotinperoxidase complex ABC Kit (diluted 1:100 in PBS) for $1 \mathrm{~h}$, in the dark and at room temperature. Sections were then rinsed and preincubated in $3,3^{\prime}$-diaminobenzidine tetrahydrochloride (DAB) in PBS for $5 \mathrm{~min}$. The peroxidase was visualized by adding $0.004 \% \mathrm{H}_{2} \mathrm{O}_{2}$ to the DAB solution for 2-4 $\mathrm{min}$. Sections were finally washed five times (1 $\mathrm{min}$ each) with PBS, mounted on gelatin-chrome alum-subbed slides, air dried, dehydrated in ethanol, cleared in xylenes, and coverslipped with Depex (EMS).

Retinogeniculate projection patterns analysis. For eye-specific segregation studies in the $\mathrm{dLGN}, \mathrm{CB} 1 \mathrm{R}^{-/-}$, and $\mathrm{CB} 1 \mathrm{R}^{+/+}$adult mice were injected with the $\mathrm{B}$ fragment of the cholera toxin $(\mathrm{CTb})$ conjugated to Alexa-546 (CTb-546; red) into the left eye and CTb-488 (green) into the right eye (1.5-2 $\mu \mathrm{l} ; 0.5 \%$ in sterile saline) (supplemental Fig. $4 A, D$, available at www.jneurosci.org as supplemental material). Forty-eight hours later, brain tissue was harvested and postfixed overnight in $4 \%$ PFA, cryoprotected in $30 \%$ sucrose, and then sectioned coronally at 40 $\mu \mathrm{m}$ thickness, mounted onto slides, and coverslipped with ImmuMount. Images were collected and quantified by an observer "blind" to the experimental conditions to minimize any bias. Universal gains and exposures were established for each label. Raw images of the dLGN were imported to Matlab and an area of interest comprising the dLGN was cropped excluding the ventral LGN and the intergeniculate leaflet; then, the degree of left and right eye projection overlap was quantified using an established multithreshold method of analysis (Torborg and Feller, 2004; Bjartmar et al., 2006; Stevens et al., 2007). This approach best permits the analysis of overlapping regions independent of the threshold. Values are expressed as the mean \pm SEM. Significance of differences between means was evaluated by Student's $t$ test analysis (Systat).

Quantification method. Photomicrographs were taken with an inverted Olympus IX71 microscope (Olympus Canada) and an Evolution VF camera (Media Cybernetics). Images were analyzed with Image Pro Plus 5.1 image analysis software (Media Cybernetics). Axon branch growth was quantified on consecutive photomicrographs of coronal slices of brain tissue comprising the dorsal terminal nucleus (DTN). On each photomicrograph, the distance between the lateral border of the nucleus of interest and the tips of the longest axon branches were measured (supplemental Fig. $4 B$, available at www.jneurosci.org as supplemental material). To account for differences in brain sizes, axon branch lengths were normalized with the interthalamic distance (distance between the right and left lateral borders of the thalamus). Axon collateral number was quantified on consecutive photomicrographs comprising the DTN using an adaptation of the Sholl technique (supplemental Fig. $4 C$, available at www.jneurosci.org as supplemental material) (Sholl, 1953). Values are expressed as the mean \pm SEM. Statistical significance of differences between means was evaluated by ANOVA with Bonferroni's post hoc test (Systat). 


\section{A Retinal explant projections}
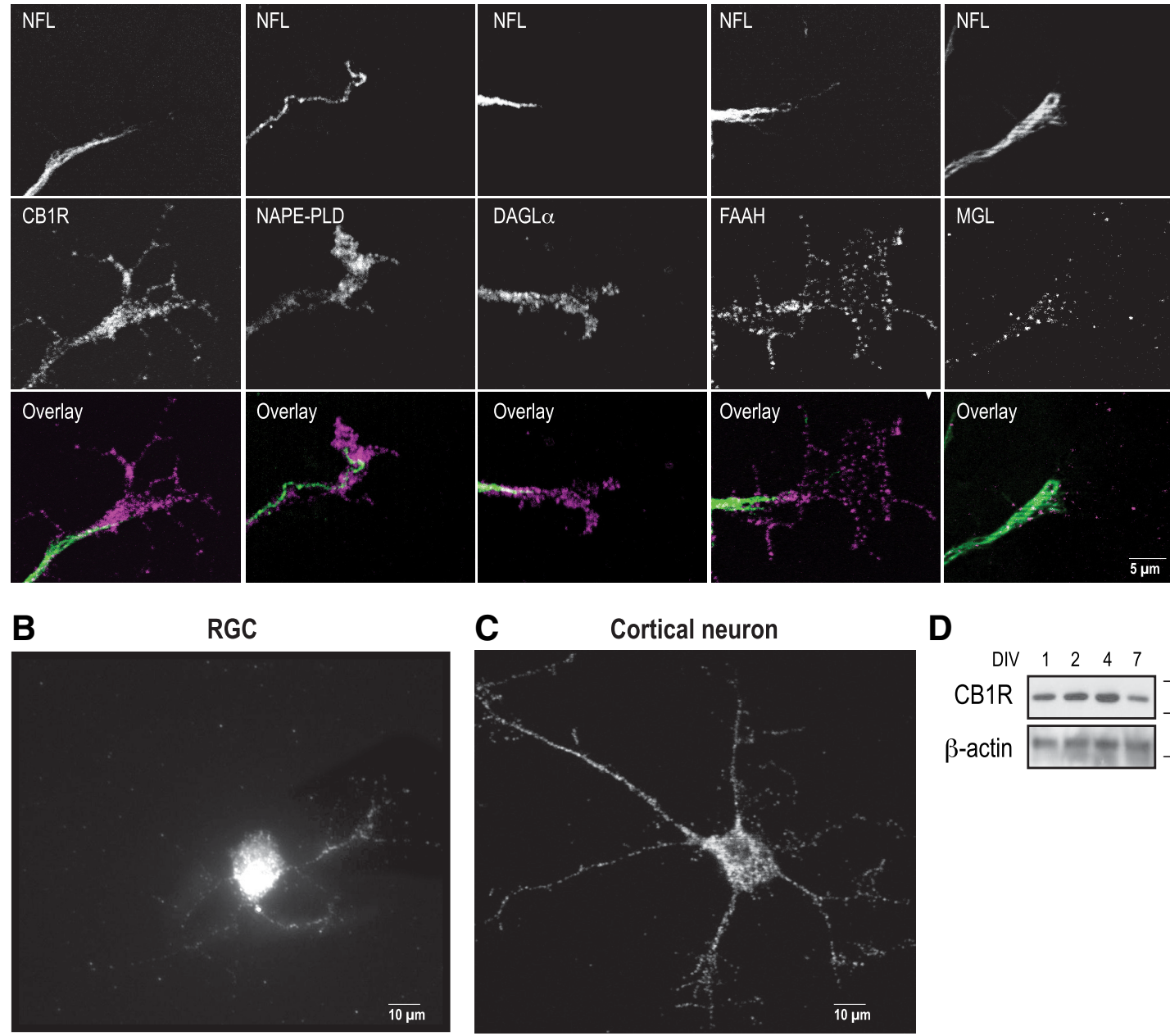

D

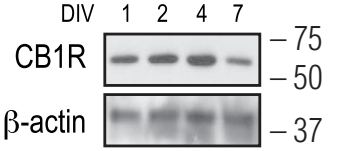

Figure 1. Expression of the eCB system in retinal projections. $A$, Retinal ganglion cell projections of E14-E15 mice retinal explants cultured for 1 DIV and immunolabeled for CB1R, NAPE-PLD, DAGL $\alpha$, FAAH, MGL, and NFL. B, C, A retinal ganglion cell and a primary cortical neuron immunostained for CB1R. D, Western analysis of CB1R expression in primary cortical neuron cultures at different DIVs. Molecular weight markers are indicated on the right side of the panel.

For cAMP immunoreactivities, all photomicrographs of GCs were taken using the same microscope, objective lens, and exposure time to allow comparison of measurements. Fluorescence intensity at the GC was corrected for background noise and quantified using Image Pro Plus 5.1 software. Values are expressed as the mean \pm SEM. Statistical significance of differences between means was evaluated by ANOVA with Bonferroni's post hoc test (Systat).

\section{Results}

The developing visual system expresses the CB1R and the eCB-synthesizing and -degrading enzymes

To explore the involvement of the $\mathrm{eCB}$ system during retinal projection guidance, E14-E15 mice retinas were dissected and cultured. We then examined the expression of the CB1R, the eCB-synthesizing enzymes NAPE-PLD [one of the enzymes implicated in anandamide (AEA) synthesis] and DAGL $\alpha$ [2-arachidonoylglycerol (2-AG)-synthesizing enzyme], and the eCB-degrading enzymes FAAH (AEA) and MGL (2-AG). These components of the eCB system were found to be expressed in the retinal projection axons as indicated by the colocalization of their immunoreactivities with NFL labeling (Fig. 1A). CB1R and FAAH were expressed in the GCs and filopodia, while NAPEPLD, DAGL $\alpha$, and MGL were mainly restricted to the retinal projection GCs (Fig. 1A). Furthermore, the CB1R is present in purified cultures of RGCs (Fig. 1B). Components of the eCB system were also investigated in primary cultures of cortical neurons. CB1R, DAGL $\alpha$, and MGL were localized in cortical neuron cell bodies, neurites, and GCs (Fig. 1C; supplemental Fig. $1 A$, available at www.jneurosci.org as supplemental material), and $\mathrm{CB} 1 \mathrm{R}$ continued to be expressed for several days in vitro as shown by Western analysis (Fig. $1 D$; supplemental Fig. $1 B$, available at www.jneurosci.org as supplemental material).

To explore the implication of the $\mathrm{eCB}$ system during retinal axon guidance, the spatiotemporal expression of CB1R, NAPEPLD, DAGL $\alpha$, FAAH, and MGL was investigated in the retinal ganglion cell fiber layer (supplemental Fig. $1 C$, available at www. jneurosci.org as supplemental material). During early postnatal development, these proteins are expressed in the retina (supplemental Fig. $1 C$, available at www.jneurosci.org as supplemental material), optic chiasm, dLGN, and SC [our unpublished data and Argaw et al. (2009)]. In the retina, CB1R and eCBsynthesizing and -degrading enzymes are expressed in retinal axons as they localize along the RGC fibers labeled with syntaxin, an axon marker (supplemental Fig. 1C, available at www.jneurosci. org as supplemental material). Overall, we observed that during the first days of postnatal development, CB1R, NAPE-PLD, DAGL $\alpha$, FAAH, and MGL are expressed along the visual path- 
way. Together, these results indicate that the CB1R and the eCBsynthesizing and -degrading enzyme expressions are spatially and temporally coordinated with the development of RGCs and cortical neurons.

\section{Pharmacological modulation of CB1R activity affects RGC GC morphology and turning in vitro}

To assess the role of eCBs during retinal axon growth and guidance, embryonic mice retinal explants were cultured for 2 DIV, and treated with pharmacological modulators of the CB1R pathway. AEA and 2-AG are the two most characterized eCBs. They can act as agonists for the CB1R and the CB2R (Pertwee, 2005). Since the present study focuses on the contribution of the CB1R in retinal axon guidance, ACEA, a highly selective synthetic CB1R agonist, has been used for the pharmacological experiments. When primary retinal (pure glutamatergic) and cortical (mixed population of GABAergic and glutamatergic) neuron cultures were treated with ACEA, GC surface area and number of filopodia diminished significantly (Fig. $2 A-F$ ). In contrast, application of AM251, a selective CB1R inverse agonist, or O2050, a CB1R antagonist, to the cultures significantly increased GC surface and filopodia number in RGCs and cortical neurons (Fig. 2A-F). As expected, AM251 or O2050 antagonized the effects of ACEA. Forskolin, a selective activator of adenylate cyclases, increased retinal projection GC surface area and filopodia number (Fig. $2 A-F)$. To test the effects of CB1R signaling on axon growth, retinal explants were treated overnight with ACEA, AM251, or O2050. Agonist (ACEA) treatment diminished total neurite length, whereas the inverse agonist (AM251) and pure antagonist (O2050) increased total neurite growth (Fig. 2G,H). Here again, the effect of ACEA was blocked by AM251 or O2050. Together, these results indicate that the CB1R modulates GC morphology and axon growth in retinal explants.

To evaluate whether the $\mathrm{CB} 1 \mathrm{R}$ is involved in retinal axon steering, the turning assay was performed on embryonic mice retinal cultures. A microgradient application of ACEA induced GC collapse and neurite retraction, while db-cAMP, a stable analog of cAMP, a cytoplasmic messenger involved in GC steering, elicited attractive turning (Fig. $2 I-L$ ). The vehicle did not induce a significant directional GC turning. These data are in agreement with a recent study reporting the repulsive turning responses of GABAergic interneuron GCs following a CB1R agonist (WIN55,212-2) stimulation (Berghuis et al., 2007).

\section{The CB1R modulates GC morphology via the cAMP/PKA pathway}

Endocannabinoids and their CB1Rs have a diverse range of signal transduction mechanisms. Upon activation, CB1 receptors recruit distinct second-messenger cascades translating into numerous downstream kinase interactions including the Raf-1/ERK1/2 (Derkinderen et al., 2003) and PI3K/AKT (Sánchez et al., 2003; Ozaita et al., 2007) signaling pathways. The implication of these signaling cascades was tested by Western blot analysis. In addition, we also investigated the implication of the cell growthregulating signaling pathway mTOR/S6K (Jaworski and Sheng, 2006; Puighermanal et al., 2009) following CB1R stimulation. Interestingly, in primary neuron cultures, $10 \mathrm{~min}$ stimulation of the CB1R did not induce changes in ERK1/2, AKT, or S6 phosphorylation levels (Fig. $3 A, B$ ). To confirm the validity of these observations, the experiments were repeated for a 20 min stimulation period without any discernible activation of these pathways (supplemental Fig. $2 A-D$, available at www.jneurosci.org as supplemental material). Furthermore, CB1R stimulation following
$\mathrm{KCl}$-induced depolarization or insulin treatment did not result in additional changes in ERK1/2, AKT, or S6 phosphorylation levels (supplemental Fig. 2E, F, available at www.jneurosci.org as supplemental material). Since it is well documented that the stimulation of CB1Rs and subsequent activation of $\mathrm{G}_{\mathrm{i} / \mathrm{o} \alpha}$ inhibits adenylate cyclase (Irving et al., 2008), we tested whether the CB1R modulates the cAMP/PKA pathway during axon growth and guidance. ACEA stimulation induced a significant decrease in cAMP levels at the GC, whereas AM251, O2050, and FSK increased them, as indicated by fluorescence intensity (Fig. 3C,D). Furthermore, PKA phosphorylation was significantly lower following ACEA stimulation, while the opposite was true after AM251 application as indicated by Western blot analysis (Fig. $3 E, F$ ). To further assess the implication of the cAMP/PKA pathway, primary neuron cultures were first treated with PKA-selective inhibitors followed by pharmacological manipulation of the CB1R. PKA inhibition blocked AM251-induced increases in GC surface area and filopodia number (Fig. 3G-I). ACEA reversed FSK-induced GC surface and filopodia increases (Fig. 3GI). These data demonstrate that CB1R activation modulates GC morphology via the cAMP/PKA pathway.

\section{The DCC receptor is required for CB1R-induced reorganization of the $\mathrm{GC}$}

The cAMP/PKA pathway has been suggested to influence the GC's sensitivity to netrin-1 (Ming et al., 1997). Several studies have reported that activation of PKA increases netrin-dependent recruitment of DCC to the plasma membrane (Bouchard et al., 2004; Moore and Kennedy, 2006; Bouchard et al., 2008). Our results suggest that the CAMP/PKA pathway functions as a downstream effector for eCBs during GC guidance. Since CB1R and DCC are expressed in developing neurons, it is reasonable to investigate the potential interactions between these two receptors. Previous reports showed that DCC is expressed in primary cortical neurons (Bouchard et al., 2008) and retinal projection axons and GCs (Deiner et al., 1997). Our results indicated that the CB1R and DCC are expressed in embryonic retinal explant axons, GCs, and filopodia (Fig. $4 A$ ). We further examined whether DCC and CB1R are expressed in transgenic mice in which CB1R $\left(\mathrm{CB} 1 \mathrm{R}^{-1-}\right)$ and DCC $\left(d c c^{-1-}\right)$, respectively, were functionally inactivated. Immunocytochemical and Western blot analysis clearly indicated that DCC is expressed in $\mathrm{CB} 1 \mathrm{R}^{-/-}$neurons, while CB1R is present in $d c c^{-1-}$ neurons (Fig. $4 B-E$ ). To determine whether CB1R activation modulates DCC trafficking to the plasma membrane, neuron cultures were treated with AM251, O2050, or FSK. Plasma membrane DCC was assessed by biotinylating cell surface proteins, and the relative amount of DCC present on the neuronal surface following the treatments was visualized by Western blot analysis (Fig. $4 F$ ). Interestingly, CB1R antagonist and inverse agonist significantly increased the amount of DCC at the plasma membrane (Fig. $4 F$ ). FSK also augmented the presence of DCC at the neuronal surface. To verify that CB1R-induced DCC trafficking is upstream or downstream of PKA activation, neuronal cultures were treated with KT5720+AM251, H89+AM251, KT5720+FSK, or H89+FSK. As visualized by Western blot, inhibition of PKA abolished AM251, O2050, and FSK-induced increases in DCC at the plasma membrane (Fig. $4 F$ ). To determine whether DCC is required for CB1R-induced reorganization of GC morphology, primary neuron cultures were exposed to DCC function-blocking antibody $(\alpha \mathrm{DCCfb})$ for $15 \mathrm{~min}$ before the addition of CB1R modulators. $\alpha$ DCCfb blocked AM251- and O2050-induced GC area and filopodia number increases (Fig. 4, $G$ and $H$, respectively; supplemental Fig. $3 A$, available at www.jneurosci.org as supplemental 


\section{A RGC projections}
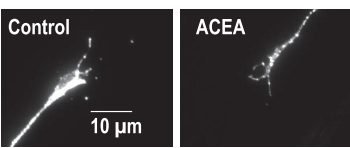

B RGC projections

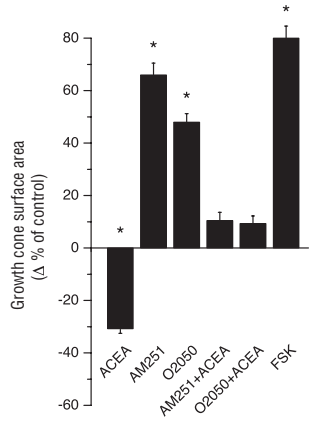

\section{G Retinal explants}
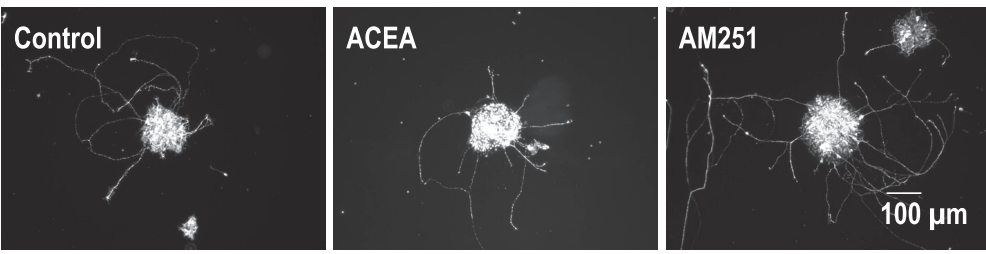

I

$$
\mathrm{T}=0 \mathrm{~min}
$$
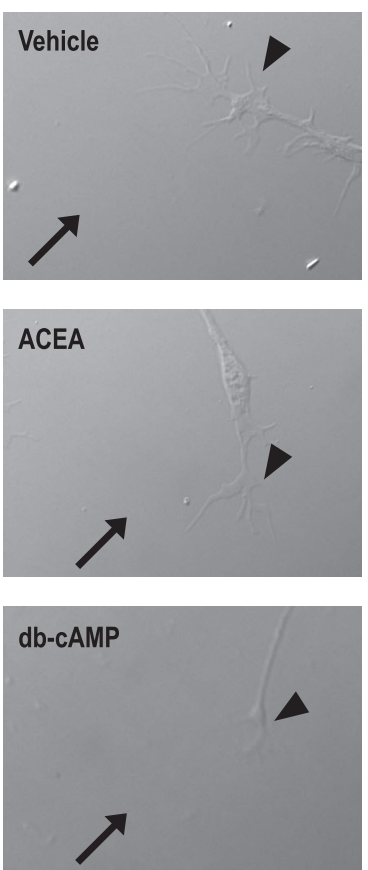
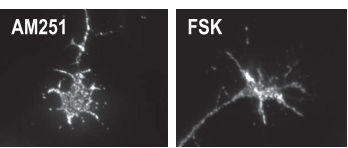

C RGC projections

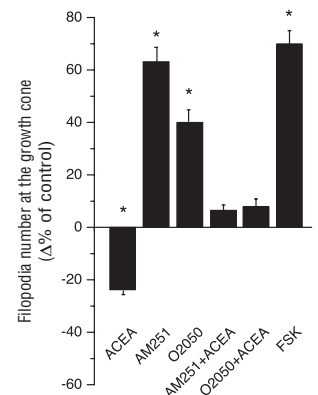

E Cortical neurons

I'
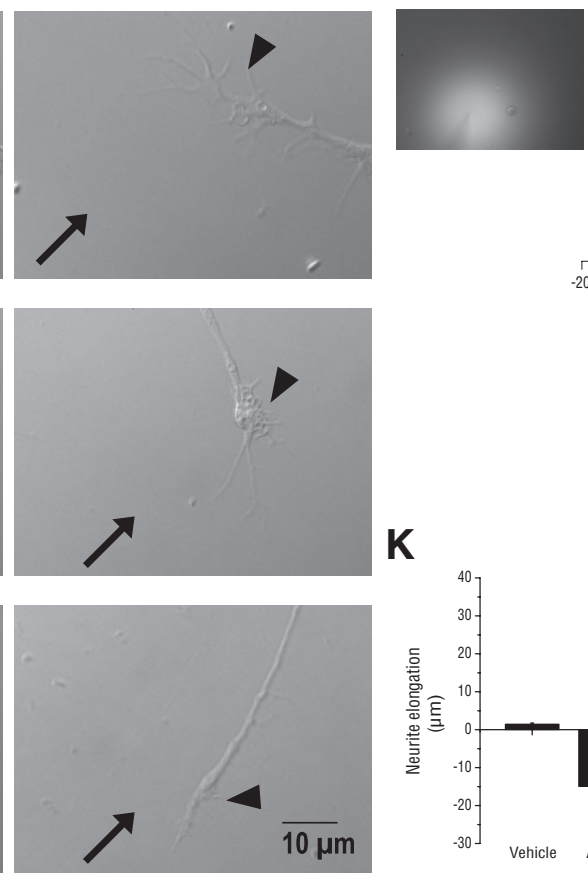

D Cortical neurons
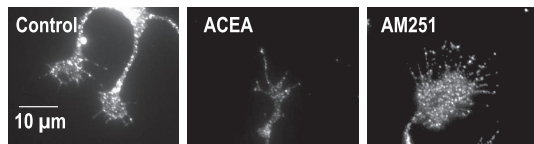

F Cortical neurons
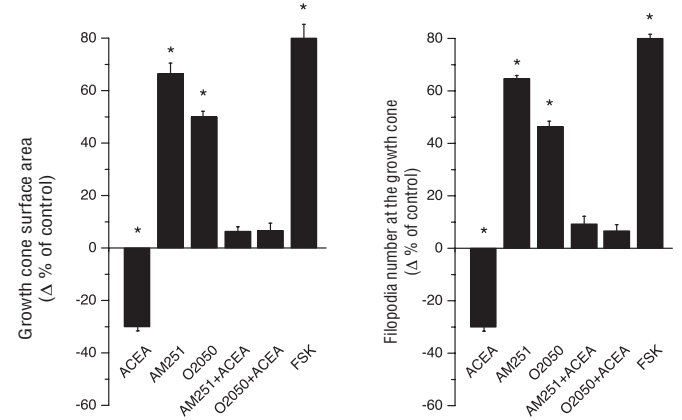

H Retinal explants

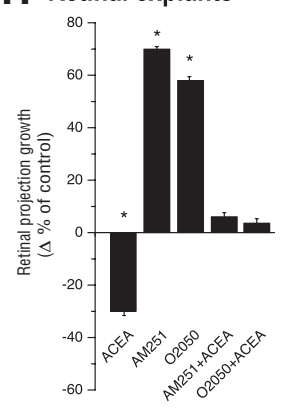

J
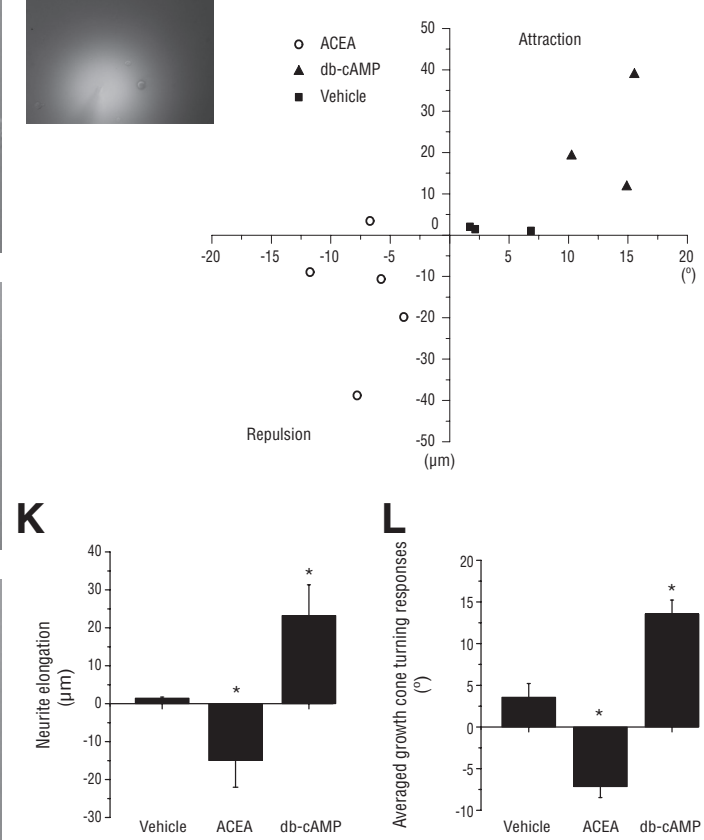

Figure 2. Pharmacological activation and blockade of the $(B 1 R$ reorganizes the morphology of the $G C$ and modulates axonal growth and navigation. $A, D$, Photomicrographs of retinal projection GCS cultured for 1 DIV $(\boldsymbol{A})$ and of primary neurons cultured for 2 DIV (D) treated with a CB1R agonist (ACEA), an inverse agonist (AM251), an antagonist (02050), or FSK. $B$, $C$, $\boldsymbol{E}, \boldsymbol{F}, \mathrm{GC}$ surface area and filopodia number analysis following a 60 min pharmacological treatment of retinal explant $(\boldsymbol{B}, \boldsymbol{C})$ and cortical neuron cultures $(\boldsymbol{E}, \boldsymbol{F})$. $\boldsymbol{G}$, Photomicrographs of retinal explant cultures treated with ACEA or AM251. H, Quantification of retinal projection growth subsequent to treatments with CB1R agonist or inverse agonist. I, Photomicrographs of RGC projection $\mathrm{GCs}$ taken at $t=0$ min and 60 min during $\mathrm{GC}$ turning assay experiments. Arrows indicate the direction of the microgradient, while arrowheads show the neurite stimulated. $I^{\prime}$, Representative photomicrograph of the microgradient created during drug stimulation. J, Scatter plot analysis of GC behavior as a result of CB1R agonist, db-cAMP, or vehicle application. $\boldsymbol{K}, \boldsymbol{L}$, Quantifications of neurite elongation and $\mathrm{GC}$ turning responses following drug stimulation. Values are presented as means \pm SEM. * indicates a significant change compared with the control group, $p<0.01(\boldsymbol{B}, \boldsymbol{C}, \boldsymbol{E}, \boldsymbol{F}, \boldsymbol{H})$. 

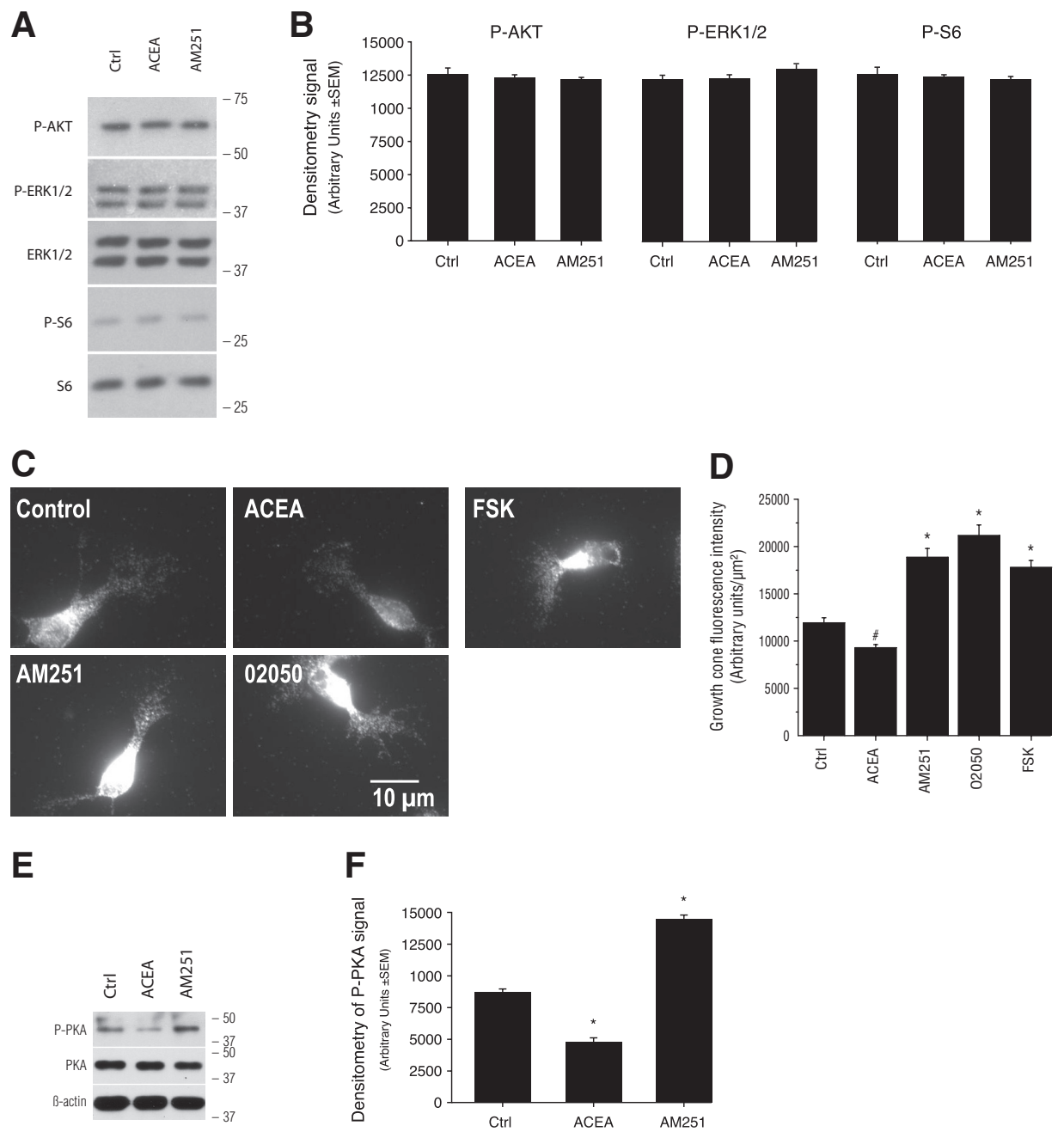

G
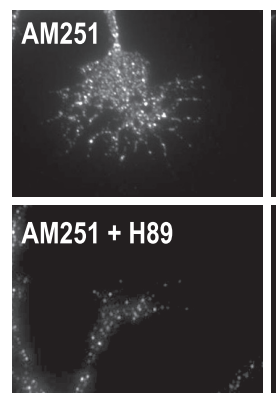

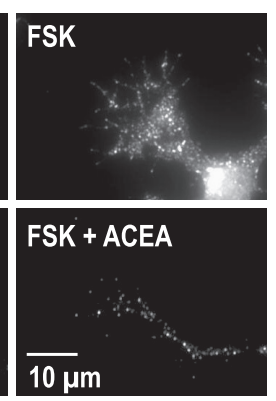

H

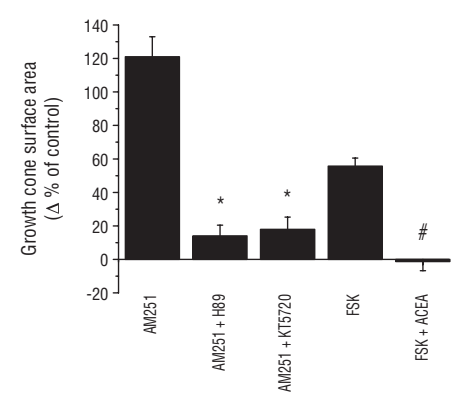

I

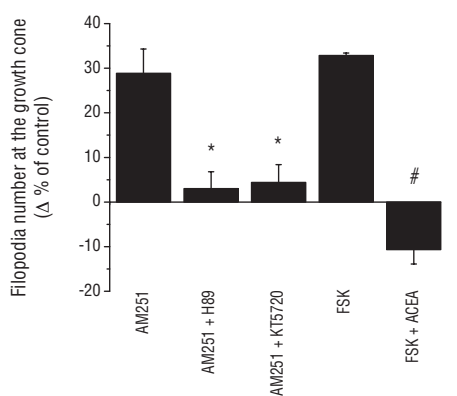

Figure 3. The CB1R modulates growth cone morphology through the CAMP/PKA pathway. $A$, Western blot analysis of downstream kinases previously suggested to modulate eCB action. Molecular weight markers are indicated on the right side of the panel. B, Quantification of the optical density for P-AKT, P-ERK1/2, and P-S6 following 10 min stimulation with ACEA or AM251. C, Photomicrographs of cortical neuron cultures immunolabeled for cAMP following 15 min stimulation with ACEA, AM251, 02050, or FSK. D, Quantification of cAMP fluorescence intensity at the GC. \# and ${ }^{*}$ indicate significant changes compared with the control group, $p<0.05$ and $p<0.0001$, respectively. E, Western blot analysis of PKA phosphorylation following 10 min stimulation with ACEA or AM251. Molecular weight markers are indicated on the right side of the panel. F, Quantification of the optical density for P-PKA. G, Photomicrographs of GCS treated with CB1R inverse agonist and agonist, FSK and PKA inhibitors. $H, I, G C$ surface area and filopodia analysis subsequent to the addition of a CB1R inverse agonist and simultaneous inhibition of PKA or the activation of PKA and the addition of a CB1R agonist. Values are presented as mean \pm SEM. * indicates a significant change compared with the AM251 group and \# with the FSK group ( $p<0.0001$ ).

material). These effects were also observed for FSK (Fig. 4G,H). The importance of DCC for eCB-mediated axon development was further investigated in transgenic mice for DCC function $\left(\mathrm{dcc}^{-/-}\right)$and their wild-type $\left(\mathrm{dcc}^{+/+}\right)$littermates. Pharmacological modulation of the CB1R did not induce any significant changes in either GC surface area or filopodia number in primary neuron cultures obtained from $d c c^{-l-}$ mouse embryos (Fig.
$4 I, K$; supplemental Fig. 3B, available at www.jneurosci.org as supplemental material). In contrast, ACEA induced a decrease in GC surface and filopodia number, while AM251, O2050, and FSK augmented these endpoints in $\mathrm{dcc}^{+/+}$neuron cultures (Fig. $4 \mathrm{~J}, \mathrm{~L}$; supplemental Fig. $3 C$, available at www.jneurosci.org as supplemental material). Together, these results demonstrate that DCC is required for CB1R-mediated GC reorganization during axon 
guidance and development. Furthermore, these findings unravel the mechanism by which cannabinoids modulate guidance cue-regulated GC steering (supplemental Fig. $4 E$, available at www.jneurosci.org as supplemental material).

The CB1R plays an important role during retinal projection growth and target selection in vivo

To assess the contribution of the eCB system during retinal projection development in vivo, hamsters received intraocular injections of CB1R modulators. Compared with rats and mice, hamsters have shorter gestation period. Consequently, they are born with a relatively premature nervous system (Clancy et al., 2001). At birth (P0), RGC axons have not all reached their thalamic and midbrain targets. By P3, virtually all RGC axons have reached their targets (Bhide and Frost, 1991). To take advantage of this opportunity, within $24 \mathrm{~h}$ following birth, hamsters received a unilateral intraocular injection of either ACEA or AM251. At P5, immunohistological experiments revealed that interfering with the eCB signaling system could have detrimental effects on RGC axon development. Compared with the control group, intraocular injection of ACEA induced a significant decrease in RGC axon branch growth in the DTN without differences in branch number (Fig. 5A-C). AM251 increased RGC collateral length and branch number in the DTN (Fig. 5A$C)$. In addition, interfering with the intrinsic ocular cannabinoid signaling with AM251 induced aberrant projections in the ipsilateral side of the SC as indicated by a robust labeling of retinal axons (Fig. 5D).

During perinatal development, RGCs from both eyes send axons that connect to multiple target cells in the dLGN. These projections spread throughout the dLGN sharing common terminal space. During postnatal development, an eye-specific segregation occurs (Godement et al., 1984). In the adult rodent, RGC axons occupy distinct eye-dependent nonoverlapping regions of the dLGN. The implication of the CB1R during retinogeniculate development was further investigated in the dLGN in adult CB1Rdeficient mice $\left(\mathrm{CB}_{1} \mathrm{R}^{-1-}\right)$ and their wildtype $\left(\mathrm{CB}_{1} \mathrm{R}^{+/+}\right)$littermates. The area occupied by contralateral projections is larger in $\mathrm{CB}_{1} \mathrm{R}^{-/-}$mice than in $\mathrm{CB} 1 \mathrm{R}^{+/+}$ mice (Fig. 5E). The contralateral and ipsilateral retinal projection images were quantified using a multithreshold method of analysis with MatLab software. These
A
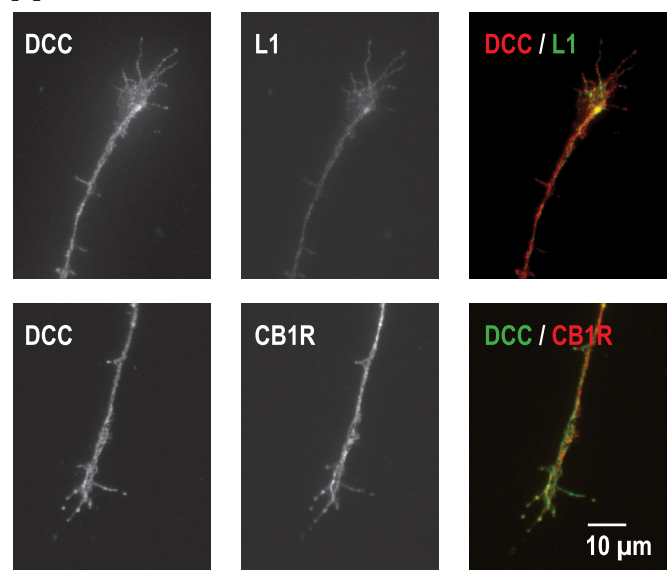

B

C
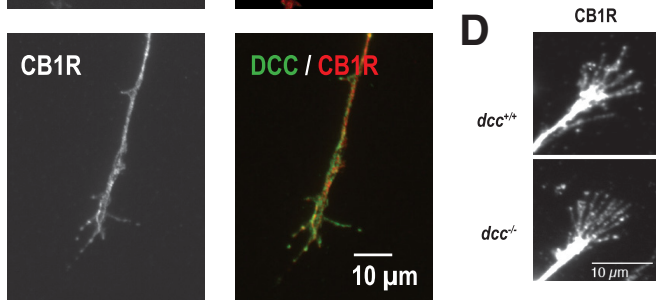

E
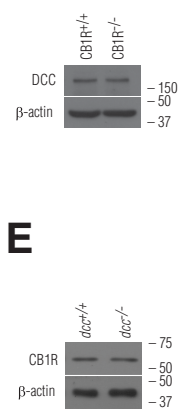

$\mathbf{F}$
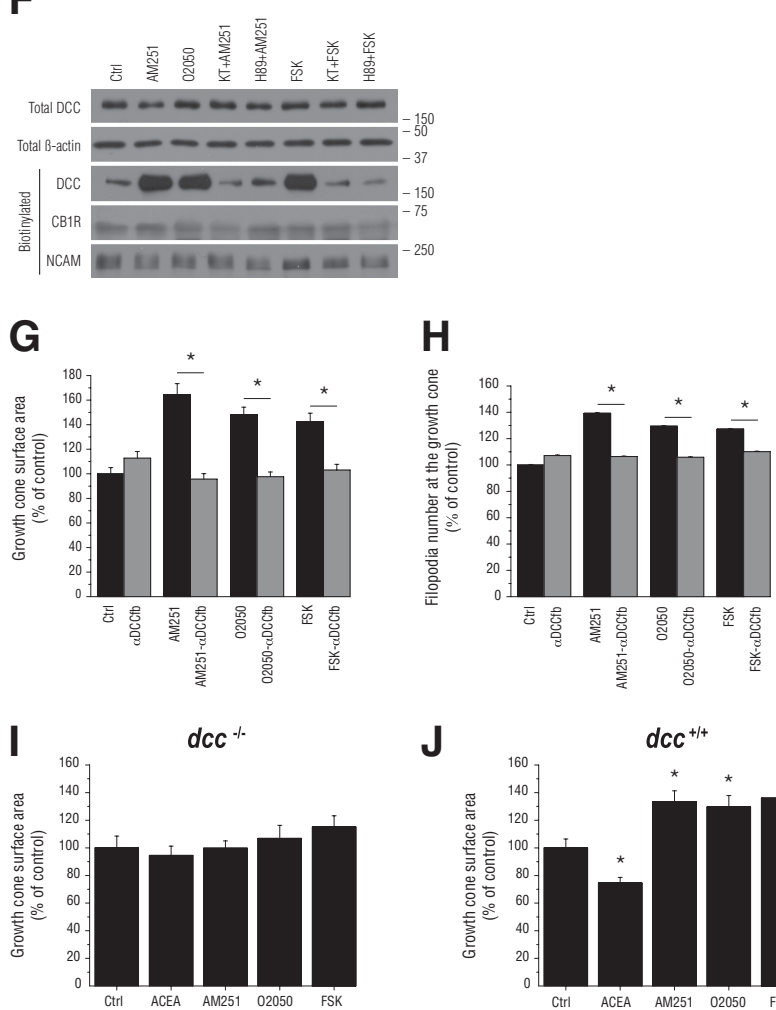

J
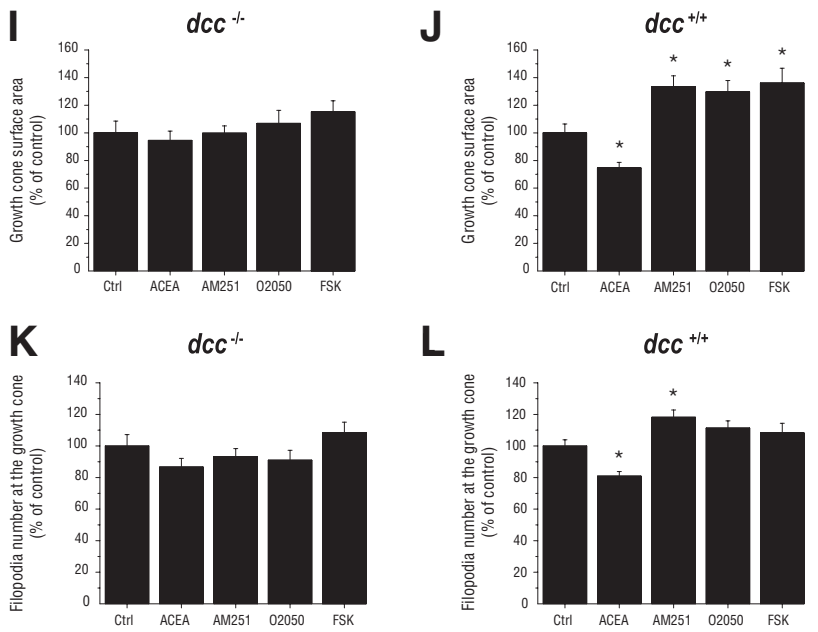

Figure 4. $D C C$ is necessary for CB1R-induced reorganization of the GC. $A$, E14-E15 mice RGC projections immunolabeled for $D C C, C B 1 R$, and L1. B, C, Immunocytochemical and Western blot analysis of DCC expression in primary retinal neuron cultures obtained from $\mathrm{CB} \mathrm{R}^{-1-}$ mice. $\boldsymbol{D}, \boldsymbol{E}$, Immunocytochemical and Western blot analysis of CB1R expression in primary neuron cultures obtained from $\mathrm{dcc}^{-1-}$ mice. $\boldsymbol{F}$, Total and biotinylated proteins analyzed by Western blot with antibodies directed against either DCC, $\beta$-actin, CB1R, or NCAM. For Western blots, molecular weight markers are indicated on the right side of the panel. $\mathbf{G}, \boldsymbol{H}$ GC surface area and filopodia number analysis of cortical neuron cultures treated with $\alpha \mathrm{DCCfb}$ followed by the addition of either a CB1R inverse agonist or antagonist (AM251 or 02050, respectively) or FSK. I-L, GC surface area and filopodia number analysis of $\mathrm{dcc}^{-1-}(\boldsymbol{I}, \boldsymbol{K})$ and dcc ${ }^{+/+}(\boldsymbol{J}, \boldsymbol{L})$ primary neuron cultures treated with either ACEA, AM251, 02050, or FSK. Values are presented as mean \pm SEM. * indicates a significant change compared with the AM251, 02050, or FSK in $\boldsymbol{G}$ and $\boldsymbol{H}$, and the control group in $\boldsymbol{J}$ and $\boldsymbol{L}(p<0.05)$. 
A
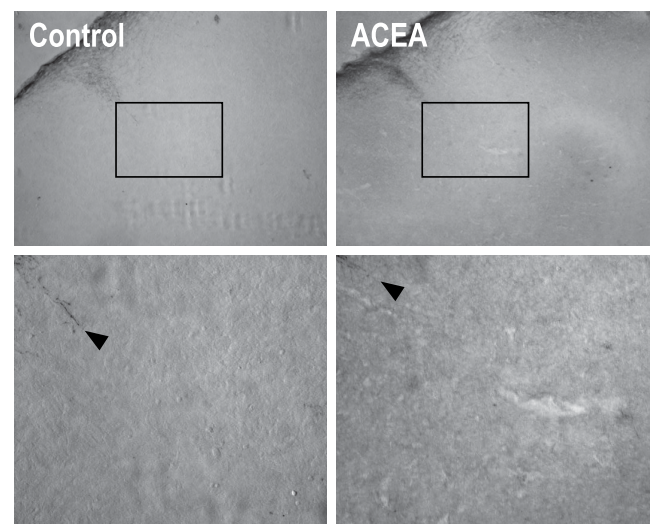

B

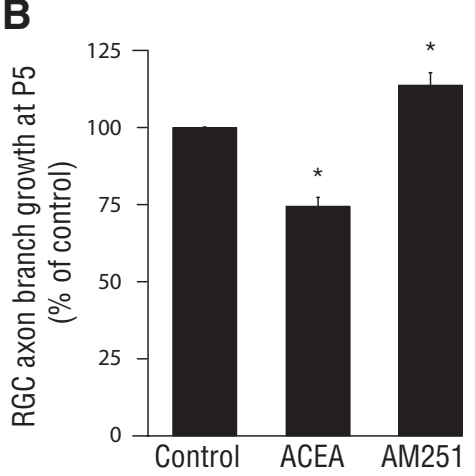

D
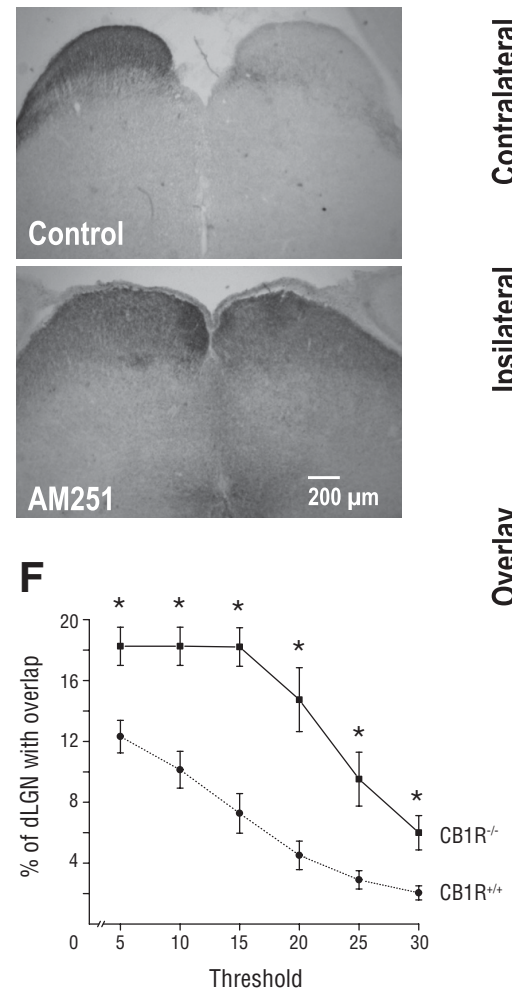

E

C
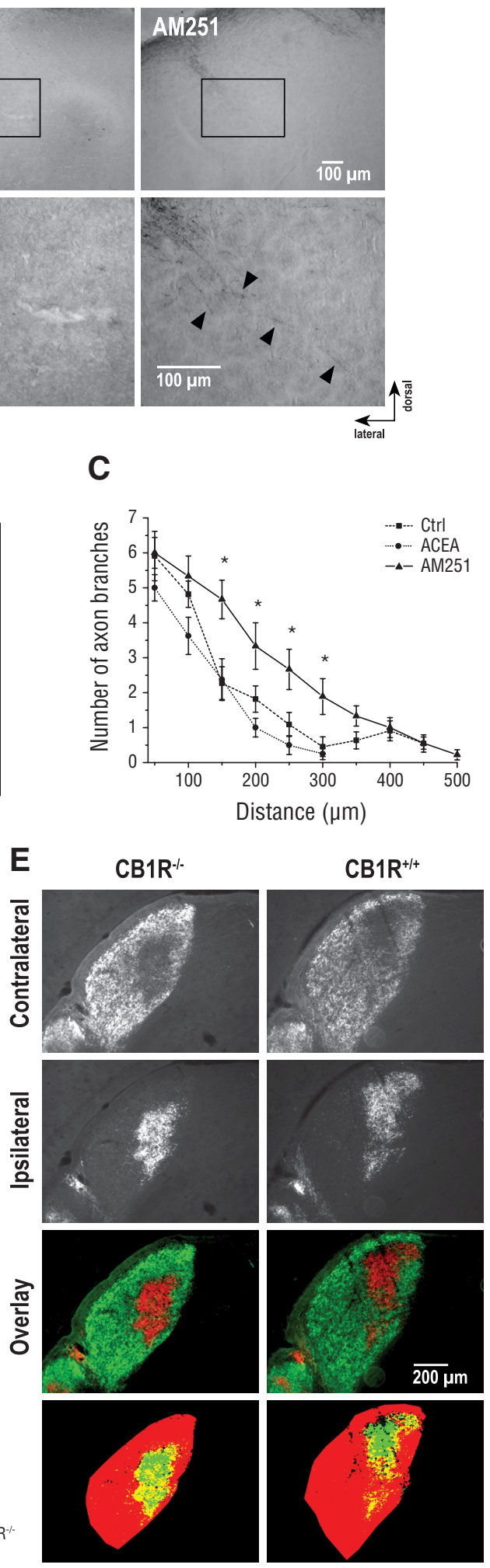

Figure 5. Pharmacological modulation of CB1R activity modulates retinal projection development in vivo. A, Photomicrographs of $\mathrm{P} 5$ retinal projections in the DTN in the control, ACEA, and AM251 groups. Lower panel shows higher magnification of retinal projections. $\boldsymbol{B}, \boldsymbol{C}$, Quantification of retinal projection development in the DTN; axon collateral growth $(\boldsymbol{B})$ and collateral branch number $(C)$ of treated groups compared with the control group. $\boldsymbol{D}$, Photomicrographs of retinal projections in the $S C$ in the control and AM251-treated groups. $\boldsymbol{E}$, Retinogeniculate projection patterns visualized following CTb conjugated to Alexa-546 (CTb-546; data indicate a significant overlap between contralateral and ipsilateral RGC projections in the dLGN of $\mathrm{CB} 1 \mathrm{R}^{-/-}$ mice (Fig. 5F). The segregation defects observed were not due to an uneven labeling of RGCs in the retina as the optic nerves of both eyes were similarly labeled following intraocular injection of anterograde tracers (supplemental Fig. $4 D$, available at www.jneurosci.org as supplemental material).

\section{Discussion}

Previously, studies have reported by in situ hybridization and immunohistochemistry the presence of the CB1R in the outer and inner plexiform, inner nuclear, and ganglion cell layers of the retina (Buckley et al., 1998; Straiker et al., 1999; Yazulla et al., 1999; Yazulla, 2008). Our observations further these studies by showing, for the first time, the presence of the CB1R and the eCB-synthesizing (NAPE-PLD and DAGL $\alpha$ ) and -degrading (FAAH and MGL) enzymes in retinal projection axons and GCs (Fig. $1 A$ ). In accordance with previous reports, we have observed the presence of the CB1R in RGCs and cortical neurons (Fig. $1 B-D$; supplemental Fig. $1 B$, available at www. jneurosci.org as supplemental material) (Lalonde et al., 2006; Vitalis et al., 2008; Keimpema et al., 2010; Wu et al., 2010). Furthermore, our findings showed that, in vivo, expression of CB1R, NAPE-PLD, DAGL $\alpha$, FAAH, and MGL is spatially and temporally synchronized with the development of RGC projections (supplemental Fig. $1 C$, available at www.jneurosci.org as supplemental material). These findings demonstrate the presence of the eCB system in the developing neurovisual system and strongly suggest its implication in retinal axon guidance and the establishment of functional retinothalamic and retinocollicular pathways.

We found that pharmacological activation or blockade of the CB1R activity modulates GC morphology of RGCs and cortical neurons (Fig. 2A-F). Accordingly, $\mathrm{CB} 1 \mathrm{R}$ agonist induced the collapse of the GC, while the CB1R antagonist or inverse agonist expanded its surface area and filopodia number of these glutama-

$\leftarrow$

red) and (Tb-488 (green) injections into left and right eyes of $\mathrm{CB}^{-/-}$and $\mathrm{CB} 1 \mathrm{R}^{+/+}$adult mice. $\boldsymbol{F}$, Quantification of the percentage of the dLGN receiving overlapping inputs in $\mathrm{CB}^{-1-}$ and $\mathrm{CB}^{-1 \mathrm{R}^{+/+}}$adult mice. Data are presented as means $\pm S E M .{ }^{*}$ indicates a significant change compared with the control group in $C(p<0.05)$ and the $\mathrm{CB} \mathrm{R}^{+/+}$group in $\boldsymbol{F}(p<0.005)$. 
tergic neurons. These data correlate with a previous study that showed CB1R agonist (WIN55,212-2)-induced GC collapse in GABAergic interneurons of the hippocampus (Berghuis et al., 2007). Additionally, our data indicate that the CB1R negatively regulates retinal projection growth (Fig. $2 G, H$ ). This is in accordance with a published study using hippocampal pyramidal neurons in which the CB1R expression was augmented by transfection (Vitalis et al., 2008). Conversely, our data are at odds with prior studies that reported that the CB1R positively regulates neurite development of cortical and cerebellar neurons (Williams et al., 2003; Mulder et al., 2008). At this point, our present understanding of the eCB system does not permit a conciliatory explanation for these discrepant results. Additionally, our results clearly demonstrate that the CB1R activity at the GC modulates retinal axon navigation (Fig. $2 I-L$ ). These results complement previously reported observations where $\mathrm{CB} 1 \mathrm{R}$ agonist treatment induced GABAergic GC collapse and retraction (Berghuis et al., 2007). Furthermore, the presence of the CB1R and the eCBsynthesizing (NAPE-PLD and DAGL $\alpha$ ) and -degrading (FAAH and MGL) enzymes in retinal axons and GCs (Fig. $1 A$ ) and the CB1R-induced retinal GC steering (Fig. $2 I-L$ ) suggest that these neurons may use target-derived as well as cell-autonomous eCBs as directional cues for GC steering decisions. These findings are in accordance with the rationale proposed by Mulder et al. (2008) that eCB-controlled axonal growth in glutamatergic cells is primarily a cell-autonomous mechanism, while GABAergic neurons use target-derived cues for directional navigation. The divergence in the mechanism used by glutamatergic and GABAergic neurons could in part be explained by the cell type-dependent regulation of eCBs. Indeed, Walker et al. (2010) reported that DAGL $\alpha$ expression diminishes dramatically once the neural stem cells differentiate in GABAergic phenotype. Furthermore, the recent work by Keimpema et al. (2010) showed the importance of the spatial and temporal expression of MGL, whereby axonal pathfinding is regulated. Furthermore, these findings highlight the intricate mechanism by which the eCB system modulates the development of various neuron populations.

Previously, Berghuis et al. (2007) reported CB1R agonistinduced ERK1/2 phosphorylation in cultured interneurons, while Ozaita et al. (2007) documented the regulation of the PI3K/ AKT by cannabinoids. Recently, Puighermanal et al. (2009) showed that, in adult, CB1R expressed on GABAergic interneurons transiently modulated the mTOR/S6K pathway. Despite various experimental conditions, we were unable to obtain similar results in our cultures of primary cortical glutamatergic neurons (Fig. $3 A, B$; supplemental Fig. 2, available at www.jneurosci. org as supplemental material). Intriguingly, however, our findings showed that $\mathrm{CB} 1 \mathrm{R}$ reorganizes $\mathrm{GC}$ morphology through DCC, a receptor for netrin-1. First, CB1R and DCC are expressed at the GC, and functional deletion of DCC does not affect the expression of CB1R as indicated by immunocytochemistry and Western blot analysis (Fig. 4A-E). Second, CB1R activity influences the level of DCC present at the plasma membrane. Accordingly, blocking the constitutive CB1R activity, using the inverse agonist AM251, enhanced the level of DCC at the plasma membrane in a PKA-dependent manner (Fig. $4 F$ ). Third, the CB1Rinduced $\mathrm{GC}$ reorganization requires the presence of a functional DCC at the GC (Fig. 4G-L; supplemental Fig. 3, available at www. jneurosci.org as supplemental material). The functional implication of these findings is that the eCB system modulates axon guidance through CB1R by modulating GC's behavior to guidance cues present in its microenvironment (please refer to the working model in supplemental Fig. $4 E$, available at www. jneurosci.org as supplemental material). Since eCBs are lipophilic compounds and are rapidly metabolized following their synthesis (Willoughby et al., 1997), it is very unlikely that they establish long-range concentration gradients similar to "classical" guidance molecules such as netrin. However, based on the results obtained in the present study, eCBs play, via CB1R, a modulatory role in axon guidance by modifying the response of GC toward a source of netrin. For instance, in spite the presence of netrin-1, an attractive guidance molecule, eCBs could induce retraction in part by downregulating the level of DCC at the plasma membrane. Furthermore, Berghuis et al. (2007) showed that CB1R induces growth cone collapse by activating RhoA, while Moore et al. (2008) provided evidence that RhoA inhibits DCC-dependent axon outgrowth to netrin. Thus, we believe that the CB1R-induced GC collapsing response observed in the present study is mediated by GTPases. Further studies are needed to unravel these mechanisms in detail.

In vivo, our data show that pharmacological and genetic interference with the CB1R activity profoundly affects retinal projection development and target selection. Accordingly, pharmacological manipulation of ocular eCB signaling affects retinal projection growth and navigation (Fig. $5 A-D$ ). Furthermore, the important role played by the eCB system during RGC axon guidance and target selection is demonstrated by the relative lack of eye-specific segregation of retinal projections in CB1R-deficient adult mice (Fig. $5 E, F$ ). Altogether, the present study identifies a mechanism by which the eCB system modulates retinothalamic development and offers a potential mechanism by which parental exposure to CB1R agonists such as $\Delta^{9}$-tetrahydrocannabinol, the major psychoactive constituent in cannabis, affects CNS development, with detrimental effects in the offspring.

\section{References}

Argaw A, Duff G, Boire D, Ptito M, Bouchard J-F (2008) Protein kinase A modulates retinal ganglion cell growth during development. Exp Neurol 211:494-502.

Argaw A, Duff G, Tea N, Ptito M, Bouchard J-F (2009) The endocannabinoid system modulates axon guidance and target selection during development. Soc Neurosci Abstr 35:129.8.

Barres BA, Silverstein BE, Corey DP, Chun LL (1988) Immunological, morphological, and electrophysiological variation among retinal ganglion cells purified by panning. Neuron 1:791-803.

Berghuis P, Dobszay MB, Wang X, Spano S, Ledda F, Sousa KM, Schulte G, Ernfors P, Mackie K, Paratcha G, Hurd YL, Harkany T (2005) Endocannabinoids regulate interneuron migration and morphogenesis by transactivating the TrkB receptor. Proc Natl Acad Sci U S A 102:19115-19120.

Berghuis P, Rajnicek AM, Morozov YM, Ross RA, Mulder J, Urbán GM, Monory K, Marsicano G, Matteoli M, Canty A, Irving AJ, Katona I, Yanagawa Y, Rakic P, Lutz B, Mackie K, Harkany T (2007) Hardwiring the brain: endocannabinoids shape neuronal connectivity. Science 316:1212-1216.

Bhide PG, Frost DO (1991) Stages of growth of hamster retinofugal axons: implications for developing axonal pathways with multiple targets. J Neurosci 11:485-504.

Bjartmar L, Huberman AD, Ullian EM, Rentería RC, Liu X, Xu W, Prezioso J, Susman MW, Stellwagen D, Stokes CC, Cho R, Worley P, Malenka RC, Ball S, Peachey NS, Copenhagen D, Chapman B, Nakamoto M, Barres BA, Perin MS (2006) Neuronal pentraxins mediate synaptic refinement in the developing visual system. J Neurosci 26:6269-6281.

Bottenstein JE, Sato GH (1979) Growth of a rat neuroblastoma cell line in serum-free supplemented medium. Proc Natl Acad Sci USA 76:514-517.

Bouchard J-F, Moore SW, Tritsch NX, Roux PP, Shekarabi M, Barker PA, Kennedy TE (2004) Protein kinase A activation promotes plasma membrane insertion of DCC from an intracellular pool: a novel mechanism regulating commissural axon extension. J Neurosci 24:3040-3050.

Bouchard J-F, Horn KE, Stroh T, Kennedy TE (2008) Depolarization recruits 
DCC to the plasma membrane of embryonic cortical neurons and enhances axon extension in response to netrin-1. J Neurochem 107:398-417.

Buckley NE, Hansson S, Harta G, Mezey E (1998) Expression of the CB1 and CB2 receptor messenger RNAs during embryonic development in the rat. Neuroscience 82:1131-1149.

Clancy B, Darlington RB, Finlay BL (2001) Translating developmental time across mammalian species. Neuroscience 105:7-17.

Deiner MS, Kennedy TE, Fazeli A, Serafini T, Tessier-Lavigne M, Sretavan DW (1997) Netrin-1 and DCC mediate axon guidance locally at the optic disc: loss of function leads to optic nerve hypoplasia. Neuron 19:575-589.

Derkinderen P, Valjent E, Toutant M, Corvol J-C, Enslen H, Ledent C, Trzaskos J, Caboche J, Girault J-A (2003) Regulation of extracellular signal-regulated kinase by cannabinoids in hippocampus. J Neurosci 23:2371-2382.

Ebrahim SH, Gfroerer J (2003) Pregnancy-related substance use in the United States during 1996-1998. Obstet Gynecol 101:374-379.

Fazeli A, Dickinson SL, Hermiston ML, Tighe RV, Steen RG, Small CG, Stoeckli ET, Keino-Masu K, Masu M, Rayburn H, Simons J, Bronson RT, Gordon JI, Tessier-Lavigne M, Weinberg RA (1997) Phenotype of mice lacking functional Deleted in colorectal cancer (Dcc). Nature 386:796-804.

Godement P, Salaün J, Imbert M (1984) Prenatal and postnatal development of retinogeniculate and retinocollicular projections in the mouse. J Comp Neurol 230:552-575.

Hanus LO (2009) Pharmacological and therapeutic secrets of plant and brain (endo)cannabinoids. Med Res Rev 29:213-271.

Harkany T, Keimpema E, Barabás K, Mulder J (2008) Endocannabinoid functions controlling neuronal specification during brain development. Mol Cell Endocrinol 286:S84-S90.

Inatani M (2005) Molecular mechanisms of optic axon guidance. Naturwissenschaften 92:549-561.

Irving AJ, McDonald NA, Harkany T (2008) CB1 cannabinoid receptors: molecular biology, second messenger coupling and polarized trafficking in neurons. In: Cannabinoids and the brain (Köfalvi A, ed), pp 59-73. New York: Springer.

Isenmann S, Kretz A, Cellerino A (2003) Molecular determinants of retinal ganglion cell development, survival, and regeneration. Prog Retin Eye Res 22:483-543.

Jaworski J, Sheng M (2006) The growing role of mTOR in neuronal development and plasticity. Mol Neurobiol 34:205-219.

Jutras-Aswad D, DiNieri JA, Harkany T, Hurd YL (2009) Neurobiological consequences of maternal cannabis on human fetal development and its neuropsychiatric outcome. Eur Arch Psychiatry Clin Neurosci 259:395-412.

Kano M, Ohno-Shosaku T, Hashimotodani Y, Uchigashima M, Watanabe M (2009) Endocannabinoid-mediated control of synaptic transmission. Physiol Rev 89:309-380.

Keimpema E, Barabas K, Morozov YM, Tortoriello G, Torii M, Cameron G, Yanagawa Y, Watanabe M, Mackie K, Harkany T (2010) Differential subcellular recruitment of monoacylglycerol lipase generates spatial specificity of 2-arachidonoyl glycerol signaling during axonal pathfinding. J Neurosci 30:13992-14007.

Lalonde MR, Jollimore CA, Stevens K, Barnes S, Kelly ME (2006) Cannabinoid receptor-mediated inhibition of calcium signaling in rat retinal ganglion cells. Mol Vis 12:1160-1166.

Mackie K (2008) Signaling via CNS cannabinoid receptors. Mol Cell Endocrinol 286:S60-S65.

Marsicano G, Wotjak CT, Azad SC, Bisogno T, Rammes G, Cascio MG, Hermann H, Tang J, Hofmann C, Zieglgänsberger W, Di Marzo V, Lutz B (2002) The endogenous cannabinoid system controls extinction of aversive memories. Nature 418:530-534.

Meyer-Franke A, Kaplan MR, Pfrieger FW, Barres BA (1995) Characterization of the signaling interactions that promote the survival and growth of developing retinal ganglion cells in culture. Neuron 15:805-819.

Ming G-l, Song H-j, Berninger B, Holt CE, Tessier-Lavigne M, Poo M-m (1997) cAMP-dependent growth cone guidance by netrin-1. Neuron 19:1225-1235.

Moore SW, Kennedy TE (2006) Protein kinase A regulates the sensitivity of spinal commissural axon turning to netrin-1 but does not switch between chemoattraction and chemorepulsion. J Neurosci 26:2419-2423.

Moore SW, Correia JP, Lai Wing Sun K, Pool M, Fournier AE, Kennedy TE
(2008) Rho inhibition recruits DCC to the neuronal plasma membrane and enhances axon chemoattraction to netrin 1. Development 135:2855-2864.

Mulder J, Aguado T, Keimpema E, Barabás K, Ballester Rosado CJ, Nguyen L, Monory K, Marsicano G, Di Marzo V, Hurd YL, Guillemot F, Mackie K, Lutz B, Guzmán M, Lu H-C, Galve-Roperh I, Harkany T (2008) Endocannabinoid signaling controls pyramidal cell specification and longrange axon patterning. Proc Natl Acad Sci U S A 105:8760-8765.

Ono M, Murakami T, Kudo A, Isshiki M, Sawada H, Segawa A (2001) Quantitative comparison of anti-fading mounting media for confocal laser scanning microscopy. J Histochem Cytochem 49:305-312.

Ozaita A, Puighermanal E, Maldonado R (2007) Regulation of PI3K/Akt/ GSK-3 pathway by cannabinoids in the brain. J Neurochem 102:1105-1114.

Pertwee RG (2005) Pharmacological actions of cannabinoids. Handb Exp Pharmacol:1-51.

Puighermanal E, Marsicano G, Busquets-Garcia A, Lutz B, Maldonado R, Ozaita A (2009) Cannabinoid modulation of hippocampal long-term memory is mediated by mTOR signaling. Nat Neurosci 12:1152-1158.

Ryberg E, Larsson N, Sjögren S, Hjorth S, Hermansson NO, Leonova J, Elebring T, Nilsson K, Drmota T, Greasley PJ (2007) The orphan receptor GPR55 is a novel cannabinoid receptor. Br J Pharmacol 152:1092-1101.

Sánchez MG, Ruiz-Llorente L, Sánchez AM, Díaz-Laviada I (2003) Activation of phosphoinositide 3-kinase/PKB pathway by CB1 and CB2 cannabinoid receptors expressed in prostate PC-3 cells. Involvement in Raf-1 stimulation and NGF induction. Cell Signal 15:851-859.

Sanford SD, Gatlin JC, Hökfelt T, Pfenninger KH (2008) Growth cone responses to growth and chemotropic factors. Eur J Neurosci 28:268-278.

Sholl DA (1953) Dendritic organization in the neurons of the visual and motor cortices of the cat. J Anat 87:387-406.

Stevens B, Allen NJ, Vazquez LE, Howell GR, Christopherson KS, Nouri N, Micheva KD, Mehalow AK, Huberman AD, Stafford B, Sher A, Litke AM Lambris JD, Smith SJ, John SWM, Barres BA (2007) The classical complement cascade mediates CNS synapse elimination. Cell 131:1164-1178.

Straiker A, Stella N, Piomelli D, Mackie K, Karten HJ, Maguire G (1999) Cannabinoid CB1 receptors and ligands in vertebrate retina: localization and function of an endogenous signaling system. Proc Natl Acad Sci U S A 96:14565-14570.

Substance Abuse and Mental Health Services Administration, Office of Applied Studies (2008) Results from the 2007 National Survey on Drug Use and Health: National Findings (NSDUH Series H-34, DHHS Publication No. SMA 08-4343). Rockville, MD: Department of Health and Human Services.

Torborg CL, Feller MB (2004) Unbiased analysis of bulk axonal segregation patterns. J Neurosci Methods 135:17-26.

Vitalis T, Lainé J, Simon A, Roland A, Leterrier C, Lenkei Z (2008) The type 1 cannabinoid receptor is highly expressed in embryonic cortical projection neurons and negatively regulates neurite growth in vitro. Eur J Neurosci 28:1705-1718.

Walker DJ, Suetterlin P, Reisenberg M, Williams G, Doherty P (2010) Down-regulation of diacylglycerol lipase-alpha during neural stem cell differentiation: identification of elements that regulate transcription. J Neurosci Res 88:735-745.

Watson S, Chambers D, Hobbs C, Doherty P, Graham A (2008) The endocannabinoid receptor, $\mathrm{CB} 1$, is required for normal axonal growth and fasciculation. Mol Cell Neurosci 38:89-97.

Williams E-J, Walsh FS, Doherty P (2003) The FGF receptor uses the endocannabinoid signaling system to couple to an axonal growth response. J Cell Biol 160:481-486.

Willoughby KA, Moore SF, Martin BR, Ellis EF (1997) The biodisposition and metabolism of anandamide in mice. J Pharmacol Exp Ther 282:243-247.

Wu CS, Zhu J, Wager-Miller J, Wang S, O’Leary D, Monory K, Lutz B, Mackie K, Lu HC (2010) Requirement of cannabinoid CB(1) receptors in cortical pyramidal neurons for appropriate development of corticothalamic and thalamocortical projections. Eur J Neurosci 32:693-706.

Yazulla S (2008) Endocannabinoids in the retina: from marijuana to neuroprotection. Prog Retin Eye Res 27:501-526.

Yazulla S, Studholme KM, McIntosh HH, Deutsch DG (1999) Immunocytochemical localization of cannabinoid CB1 receptor and fatty acid amide hydrolase in rat retina. J Comp Neurol 415:80-90. 